\title{
ANÁLISE DAS DIFICULDADES DE IMPLEMENTAÇÃO DA LEI 10.639/2003 NA EDUCAÇÃO BAIANA: UMA REVISÃO SISTEMÁTICA
}

\author{
Analysis of the difficulties of implementing law $10.639 / 2003$ in baiana education: a systematic \\ review
}

\section{Adriano Martins Ribeiro ${ }^{1}$}

RESUMO: A Bahia formou-se como um território multicultural, pluriétnico, mas que ainda convive com os resquícios do processo colonizador, prevalecendo a discriminação racial e a exclusão do segmento negro da sociedade. Dessa forma, buscou-se analisar as dificuldades de implementação da Lei Io.639/2003 no ensino. Para esse fim, partiu-se de uma metodologia de sistematização de estudos bibliográficos, de forma qualitativa, produzidos nos últimos dez anos e que foram realizados em cidades baianas, trazendo os principais apontamentos responsáveis pelos entraves para inclusão do Ensino de História e Cultura da África e Afro-brasileira nas escolas de ensino básico. Assim, as principais dificuldades na implementação da referida legislação foram a falta de desconhecimento da lei que rege o ensino étnico-racial, a falta de preparo acadêmico dos docentes, material didático inexistente ou incompleto e a falta de inclusão de políticas públicas mais eficientes para erradicar o racismo a partir de um ensino plural e universal.

Palavras-chave: Educação. Impactos. Relações étnico-raciais. Lei 10.639/2003.

ABSTRACT: Bahia was formed as a multicultural, multi-ethnic territory, but it still coexists with the remnants of the colonizing process, with racial discrimination and the exclusion of the black segment of society prevailing. Thus, we sought to analyze the difficulties of implementing Law 10,639/2003 in education. To this end, it was based on a methodology of systematization of bibliographic studies, in a qualitative way, produced in the last ten years and that were carried out in cities of Bahia, bringing the main notes responsible for the obstacles to the inclusion of the Teaching of History and Culture of Africa and Afro-Brazilian in basic education schools. Thus, the main difficulties in implementing this legislation were the lack of knowledge of the law governing ethnic-racial education, the lack of academic preparation of teachers, nonexistent or incomplete teaching material, and the lack of inclusion of more efficient public policies to eradicate racism from a plural and universal education.

Keywords: Education. Impacts. Ethnic-racial relations . Law ro.639/2003.

\section{INTRODUÇÃO}

O Brasil é considerado um dos países mais miscigenados que existe, seja decorrente de sua composição inicial, formada pela variação étnica dos povos indígenas que aqui estavam, dos portugueses e dos povos africanos trazidos na condição de escravos, ou decorrente de um território extenso,

\footnotetext{
I Bacharel em Direito pela Faculdade Pitágoras de Teixeira de Freitas- BA, especialista em Direito do Trabalho e Previdenciário pela Universidade Pitágoras Unopar, Especialista em Docência do Ensino Superior, pós-graduando em Educação e Direitos Humanos pelo Instituto Brasileiro de Formação (2020). E-mail: adrianno_martins@hotmail.com.
} 
praticamente de tamanho continental, permitindo que diversas etnias possam aqui residir e se adaptar às condições naturais, econômicas e típicas da localidade (RIBEIRO, 2005). No entanto, ainda que essa mistura de raças e cores seja típica do brasileiro, é notória a presença de atitudes de racismo, preconceito e discriminação, segregando as pessoas ao favorecer algumas por serem brancas e possuírem um poder econômico-aquisitivo maior, enquanto outras, negros, índios ou oriundos de situações de vulnerabilidades sociais, são marginalizados, desprotegidos e alocadas em condições subumanas de habitação, escolaridade e trabalho.

Visando buscar uma solução para os problemas da discriminação pela cor da pele, pela orientação sexual, pela etnia a que se pertence ou mesmo pela religião que se professa, através da inclusão, foi proposta e aprovada a Lei 10.639 , em o9 de janeiro de 2003, que altera a Lei de Diretrizes e Bases da Educação (LDB), instituindo a obrigatoriedade do ensino de História e Cultura Africana e Afrobrasileira nos currículos da educação básica, em especial nos currículos de Língua Portuguesa e Literatura, História e Educação Artística (BRASIL, 2003). Dessa forma, é pelo ensino que se desconstrói os estigmas da ignorância do racismo e da discriminação ao mesmo tempo que constrói cidadãos capazes de pensar de forma coletiva, no próximo e entendendo que somos todos uma raça, a raça humana.

A Bahia possui uma grande representatividade étnica, decorrente de sua multiculturalidade e do pluralismo de ideias que coexistem em seu território. Porém, observou-se que muitos são os desafios para implementar a lei no Estado, onde ainda persistem resquícios do processo colonizador, coexistindo problemas sociais decorrentes principalmente da discriminação racial. Ainda que se observe a presença da cultura negra de forma tão presente, seja na comida, na dança, na fé ou na transferência de conhecimentos, é preciso verificar se os preceitos da Lei $10.639 / 2003$ estão surtindo efeitos dentro e fora das escolas de ensino básico, contribuindo para quebrar paradigmas enraizados na sociedade (ARAUJO, 2015).

O problema que delineou este estudo se baseou no seguinte questionamento: quais as principais dificuldades para a implementação da Lei Io.639/2003 nas escolas de ensino básico na Bahia, a partir de estudos realizados nos últimos dez anos?

Objetivou-se, de forma geral, por meio de uma revisão integrativa, compreender qual o impacto ocasionado pela Lei ro.639/2003 no ensino Básico no Estado da Bahia. De forma específica, procurou-se levantar estudos realizados sobre os impactos da Lei $10.639 / 2003$ no ensino em munićpios da Bahia; sistematizar os estudos sobre a transversalidade da Lei que rege o ensino de História e Cultura Africana e Afro-brasileira no ensino básico; e, reunir os dados obtidos sobre as dificuldades das ações em sala de aula 
para a aplicação da Lei, visando apontar o que precisa ser feito para que a referida legislação provoque resultados positivos na sociedade.

A metodologia partiu da análise bibliográfica de textos secundários, de forma qualitativa, de produções científicas produzidas nos últimos dez anos em periódicos indexados, bem como autores que compilam conhecimentos sobre a História, a Cultura Africana e afro-brasileira e a sua formação, e aqueles autores que analisaram a aplicabilidade da Lei 10.639/2003 no ensino básico em Municípios do Estado da Bahia, a exemplo de Souza, Santos e Eugênio (2015), Santana et al. (2017), Lima (2020), Souza (2017) e Gomes (2020).

\section{A lei $10.639 / 2003$ e o seu impacto na educação básica: dificuldades e desafios}

A principal justificativa para a criação de uma lei que trate da obrigatoriedade do ensino da História e da Cultura da África e dos afro-brasileiros nos currículos do ensino básico, especificamente a Lei Federal no $10.639 / 2003$, de o9 de janeiro de 2003, foi para buscar minimizar, ainda que de forma ínfima, os mais de trezentos anos de escravidão a negros e índios, considerados subumanos. Ao reformar a Lei de Diretrizes e Bases da Educação Brasileira, LDB ou Lei 9.394/1996, nos termos das diretrizes curriculares nacionais para o ensino de história e cultura africana e afro-brasileira, buscou minimizar os efeitos do racismo e da discriminação a partir de um ensino agregador, que valoriza a

cultura negra e que realça desde os anos iniciais do ensino a sua importância para a formação da cultura nacional (BRASIL, 2004).

Débora Ribeiro (2015), ao trabalhar com a Lei 10.639/03, afirmou que a referida legislação foi formulada como uma resposta aos anseios trazidos pelo movimento negro, o qual reivindicou junto aos poderes públicos amparo legal que assegurasse a equidade entre todos, brancos e negros. Ademais, a Lei que modificou a LDB buscou garantir que alunos negros também tivessem o direito de criar uma identidade positiva sobre si, tendo reconhecida a contribuição que os seus antepassados deixaram na construção da história brasileira, e acabando com a farsa da homogeneidade na escola que existia apenas no papel.

Para Gomes (2012), a presença e composição da cultura negra no País é fortemente incluída nos discursos (políticos, sociais, educacionais), independentemente da localidade. Porém, as pesquisas realizadas pelos principais órgãos do Brasil apontam que, na prática, a condição de vida, trabalho e estudo da população negra ainda é precária, com alto índice de desigualdade, com a existência de um racismo enraizado e do sofrimento provocado pela discriminação. 
Conforme dados de 2007, quase metade da população se autodeclarava negra, praticamente equiparada com aquele segmento que se autodeclarava branco. No entanto, o que se percebeu foi que mesmo havendo políticas públicas para a igualdade, ainda é alarmante o percentual de analfabetos no segmento negro da sociedade, quando comparados com o restante da população. Para a referida autora, vinculando políticas públicas e educação básica (GOMES, 2012).

Mesmo havendo a consideração sobre o processo de universalização da educação básica, o qual foi desencadeado nos últimos anos (e que ainda persiste nos dias atuais), permitindo acesso aos processos de escolarização a diversos grupos sociais, ressalvado que tal fato não muda o modo como a organização escolar básica se estrutura. Dessa forma, ainda que as políticas públicas tenham proporcionado mais acesso à educação, ainda é preocupante a discrepância da escolarização em questões raciais, onde os negros historicamente tiveram menos acesso às ações do governo, contribuindo para aumentar as desigualdades sociais (GOMES, 2012).

Conforme Almeida e Sanches (2017), a Lei 10.639/2003 é um exemplo típico de uma política de ação afirmativa. A lei, ao modificar a Legislação básica do ensino nacional, a LDB, provocou uma transformação de ordem cultura, social, ideológica, tendo como meta-fim a quebra do ideário da supremacia racial. Ademais, a legislação, ao questionar o currículo oficial, considerado um dos âmbitos de construção da política de representações de mundo, de sociedade e de pessoas, garante que cada um tenha o direito de acesso ao ensino básico no país. É partir dessas modificações que se visualizou uma garantia maior aos alunos negros para que tenham reconhecido e valorizado, de forma pessoal e simbólico, a sua identidade (BRASIL, 2004).

Para Araújo (2015), nos últimos anos houve uma preocupação maior das autoridades políticas e administrativas em criar projetos de políticas públicas para erradicar os efeitos ocasionados pela discriminação e pelo racismo, que tanto tem marginalizado as pessoas negras. Para o autor:

Assim, na busca de minimizar a situação marginal em que os grupos étnico-raciais e culturais considerados inferiores pela cultura hegemônica se encontram no país, o Estado, seus governantes e suas instituições, nos últimos anos, têm formulado políticas de ações afirmativas cujo objetivo é a equidade de direitos e de oportunidades entre todos os cidadãos e cidadãs brasileiros, bem como o combate ao racismo, ao preconceito e à discriminação, por exemplo, racial e de gênero, que permeiam a sociedade brasileira (ARAÚJO, 2015, p. 2017).

As políticas públicas não podem ser apenas "letras mortas" de uma legislação inaplicável, mas sim garantidas e efetivadas pelos poderes públicos, pelas organizações administrativas locais e cobradas por toda a sociedade, permitindo que seja cumprido o papel reparador do Estado por tantos anos negligenciando a importância da cultura africana e afro-brasileira para a construção da sociedade, ao 
mesmo tempo que repara e garante a identidade ao negro, dando-lhe igualdades de condições (ARAÚJO, 2015). Confirmando tal pensamento, Araújo afirmou que:

Em outras palavras, políticas idealizadas como medidas de promoção da igualdade de direitos e de oportunidades, reparação e combate à discriminação racial, de gênero, entre outras, que se faz presente em todas as esferas da sociedade brasileira desde a formação do Brasil. Políticas que têm contribuído significativamente para diminuir barreiras, impostas pela nossa sociedade, que dificultam a ascensão social, econômica, política e intelectual, bem como o acesso a bens e serviços negados ou negligenciados pelo Estado brasileiro aos sujeitos historicamente discriminados (ARAÚJO, 2015, p. 217).

Para fins de concretizar essa política pública a partir do ensino básico, foi proposto a Lei Io.639, aprovada em o9 de janeiro de 2003, onde "altera a Lei no 9.394, de 20 de dezembro de 1996 , que estabelece as diretrizes e bases da educação nacional, para incluir no currículo oficial da Rede de Ensino a obrigatoriedade da temática "História e Cultura Afro-Brasileira", e dá outras providências", permitindo que fosse disponibilizado ao educando do ensino básico, aquele composto pelo ensino fundamental e médio, o acesso ao papel que a população negra desempenhou na construção da soberania nacional, a qual em conjunto com outras etnias (índios, estrangeiros, portugueses) contribuíram de forma essencial para todo o patrimônio histórico-cultural nacional que existe na atualidade (BRASIL, 2003).

Buscando, de forma específica, transformar a sociedade a partir do ensino e da educação, a Lei I0.639/2003, introduziu o artigo 26-A na LDB, tornando obrigatório o ensino de conteúdo programático relativo à "história da África e dos Africanos, a luta dos negros no Brasil, a cultura negra brasileira e o negro na formação da sociedade nacional, resgatando a contribuição do povo negro nas áreas social, econômica e política pertinentes à História do Brasil” (BRASIL, 2003). Os temas serão tratados de forma transversal e obrigatório em disciplinas prioritárias do ensino básico, a exemplo de Língua Portuguesa, Literatura, História e Educação Artística.

Foi a partir do Parecer CNE/CP 003/2004 que houve uma ampliação do alcance e materialização da política antirracista trazida pela Lei $10.639 / 2003$, pois o referido ato presidencial tornou abrangente a necessidade de acesso aos conhecimentos sobre a diversidade que compõe a nossa sociedade, indo além da sala de aula, mas abrangendo toda a sociedade (BRASIL, 2004). Nesse sentido, afirmou-se que os conhecimentos ali presentes:

Destina-se, o parecer, aos administradores dos sistemas de ensino, de mantenedoras de estabelecimentos de ensino, aos estabelecimentos de ensino, seus professores e a todos implicados na elaboração, execução, avaliação de programas de interesse educacional, de planos institucionais, pedagógicos e de ensino. Destina-se, também, às famílias dos estudantes, a eles próprios e a todos os cidadãos comprometidos com a educação dos brasileiros, para nele buscarem orientações, quando pretenderem dialogar com os sistemas de ensino, escolas e educadores, no que diz respeito às relações étnico-raciais, ao reconhecimento e valorização da história e cultura dos afro-brasileiros, à diversidade da nação brasileira, ao igual direito à educação de qualidade, isto é, não apenas direito ao 
estudo, mas também à formação para a cidadania responsável pela construção de uma sociedade justa e democrática (BRASIL, 2004, p. 2).

As políticas travadas a partir dessa legislação buscaram garantir àquele que se autodeclara negro o direito de se firmar enquanto cidadão integrante da sociedade brasileira e integrantes da cultura nacional, manifestando visões de mundo, opiniões e tendo, ao mesmo tempo, o direito de igualdade à educação, podendo alcançar cada um dos níveis do ensino nacional. Garantir, ainda, aos segmentos negros da população, assim como a todos os nacionais, o pleno conhecimento para ter acesso ao mundo do trabalho, ao progresso e de possuir formação específica para se munir e se ver livre de forma de discriminação (BRASIL, 2004).

O maior desafio de implementar a Legislação que trata da obrigatoriedade do ensino da história, da cultura e da valorização da contribuição da população negra para todo o histórico nacional resida nas questões relativas às segregações seculares que acometem nosso país, tornando-o um dos países mais desiguais do mundo (ARAÚJO, 2015).

Nessa perspectiva, Araújo (2015) afirmou que, após mais de uma década da criação da Lei 10.639/2003, ainda é inóspita a sua efetividade enquanto motriz de quebra de paradigmas segregadores, decorrentes principalmente da falta de concretização de seus preceitos na maioria das escolas brasileiras. A justificativa para a falta dessa implementação nos currículos escolares, de forma efetiva enquanto política pública educacional, está atrelada a questões persisitentes de práticas do racismo em todas as suas formas, às condições precárias que ainda se encontra o ensino público no Brasil e a deficiencia na formação inicial de professores, que por serem mal preparados para tratarem das questões étnico-raciais e culturais em sala de aula, acabam perdendo uma chance de ouro para fazerem a diferença em uma sociedade altamente excludente e discriminatória (NUNES, 2014).

Almeida e Sanches (2017) afirmaram que a Lei 10.639/2003 por um lado apresenta um caráter de cunho compensatório, buscando garantir um reconhecimento àqueles que sofreram durante séculos processo escravidão e de humilhação e que na atualidade sofrem com a falta de oportunidades e com uma vida precária, com acesso limitado a inúmeros direitos fundamentais.

Por outro lado, a legislação, por si só, não é suficiente para garantir que haja a desconstrução de tantos anos de racismo institucionalizado em que se vive, pois "Não há uma relação direta e imediata entre o ensino da história e da cultura afro-brasileira e a mudança das relações sociais desiguais, mas ele pode ser instrumento de tensionamento das desigualdades raciais [...]” (ALMEIDA; SANCHES, 2017, p. 4).

A partir desse ensino da cultua do outro, da alteridade, é que se estabelece um diálogo com as diferenças, com os pontos de visão e as experiências múltiplas, quebrando a ideia de superioridade de uns 
em relação a outros, visando a desconstrução de mentalidades ou mesmo práticas discriminatórias, tornando, ao final, a sociedade mais igualitária (ALMEIDA; SANCHES, 2017).

Assim, para Gomes (2012), criar e implementar políticas sociais, em especial aquelas que dizem respeito a questões de ensino, acontecem em um ambiente altamente conflitivo da vida social, principalmente quando a temática da discussão está relacionada com questões de herança histórica e social vinculadas ao campo da formulação e implementação de políticas educacionais. Em períodos autoritários, principalmente, há uma marca ainda maior desse conflito com a presença de determinações de forma centralizada, ocorrendo um verdadeiro esvaziamento dos currículos, sem contar a tentativa de negar, de forma veemente, que não há desigualdades na sociedade, em especial aquelas mais marcantes, relativo às questões de classe, da etnia e raça, gênero ou mesmo de orientação sexual.

\section{I Aplicabilidades da legislação sobre Educação das Relações Étnico-raciais na Bahia}

A partir de um estudo mais amplo que abordou a atuação das organizações negras no Nordeste, objetivando uma reflexão sobre os entraves que dificultam a efetivação da Lei 10.639/03 nas escolas baianas, afirmou que não trabalhar os conteúdos relativos à história, à cultura, às contribuições sociais e inovações trazidas pelos africanos, pelos afro-brasileiros, índios e demais formadores do povo brasileiro, de forma crítica e amplamente debatida é o mesmo que se silenciar diante de uma temática tão importante para fins de quebrar as correntes do racismo, da discriminação e da segregação racial (ARAÚJO, 2015).

Outro ponto destacado, desta vez mais abrangente, quando se analisou a aplicabilidade da Lei 10.639/2003 no Nordeste brasileiro, verificou que a referida legislação não é desconhecida de gestores escolares e professores, mas o que se verificou é uma falta de domínio dos conteúdos pelos agentes educacionais, decorrentes principalmente de uma precária formação inicial e continuada, ou mesmo não havendo domínio das diretrizes curriculares para o ensino da História e Cultura no que se refere às relações étnico-raciais (ARAÚJO, 2015).

Dentre os problemas relatados, ainda afirmaram que os materiais disponibilizados pelo Ministério da Educação (MEC) não têm abrangência nacional quanto a temática racial, o que tem contribuído para um ensino precário, mantendo as hegemonias da sociedade excludente e tornando o racismo e a discriminação como um problema ainda mais enraizado na sociedade (ARAÚJO, 2015).

Souza, Santos e Eugênio (2015) em estudo sobre a questão étnica e racial, questionam a demora na implementação de forma efetiva pelas escolas dos preceitos obrigatórios introduzidos pela Lei Io.639/2003, onde na Bahia o percurso de inclusão nos currículos das temáticas vem ocorrendo de forma 
ainda mais lenta. Dessa forma, para os supracitados autores,

Passados mais de ro anos desta Lei, o que constatamos é que muitas redes de ensino ainda não implementaram o ensino de história e cultura africana e afro-brasileira nos planos municipais de educação, na formação continuada dos docentes e no trabalho cotidiano do currículo praticado nas escolas. Isso significa dizer que, apesar da conquista de marcos legais, a escola que a população negra conhece ainda é uma escola que tem negado a sua existência, orientada pelo esquecimento e pela invisibilidade dessa população (SOUZA; SANTOS; EUGENIIO, 2015, p. 179).

Essa dificuldade de implementar a Lei que trata do ensino da História e da Cultura do segmento negro componente da sociedade brasileira não se restringe somente à educação básica. Mas é justamente a partir da sua implementação nesse segmento que toda a sociedade sofrerá mudanças, quebrando raízes que há muito segregam brancos e negros, colocando os primeiros como superiores. Nesse interim,

A Lei no $10.639 / 03$ propõe modificações para a estrutura da própria sociedade brasileira. Partindo desse princípio, não é difícil compreender o nascedouro das dificuldades vivenciadas e enfrentadas no exercício de sua implementação. Tais dificuldades são reflexos da ideia enraizada de inferioridade do negro e superioridade do branco, que ainda na atualidade justifica o racismo e as desigualdades etnicorraciais no país, gerando reações contrarias à adoção de políticas de ação afirmativa para a população negra brasileira (SOUZA; SANTOS; EUGÊNIO, 2015, p. 183).

Souza (2015) acrescentou que a partir de suas pesquisas sobre as leis e as políticas educacionais, voltadas para uma perspectiva multicultural e antirracista, ainda que instituídas pelo Estado, não foram plenamente implementadas nos Estados brasileiros. O que se percebeu foi que na maioria dos espaços educacionais formais não há desenvolvimento de práticas educativas que efetivem as relações étnicoraciais, preceituada pelas Leis $10.639 / 2003$ e posterior modificação pela Lei II.645/2008, bem como pelas Diretrizes Curriculares Nacionais de Educação para as Relações Étnico-Raciais.

Como principal prejuízo, o supracitado autor acrescentou que, mesmo diante de tantos avanços que a educação proporcionou na sociedade, ainda é visível situações sociais que favorecem a manutenção do preconceito ou da discriminação racial, étcnica e cultural, reduzindo ou até mesmo ignorando os papéis que negros, índios e outras etnias tiveram com a formação do Brasil (SOUZA, 2015).

\section{Metodologia}

O estudo se baseia em revisão integrativa. A revisão integrativa buscará identificar, analisar e sintetizar os impactos da implementação da Lei $10.639 / 2003$ nas escolas de ensino básico na Bahia, literatura essa utilizada a partir de teóricos em bancos de dados por meio de revistas com indexação, sendo o aporte pesquisado a partir de publicações dos últimos io anos (2010 a 2020).

Com a finalidade de compreender a implementação da Lei $10.639 / 2003$ na educação baiana, analisou-se o incremento dessa legislação que alterou a LDB, modificando o currículo da educação básica 
para abarcar conteúdos relativos às questões étnico-raciais e culturais, verificando estudos feitos em escolas ou em outros espaços formais de educação em cidades da Bahia, com literatura de até io anos de publicação.

Os passos seguidos para o método investigativo foi a identificação do problema (definido claramente na introdução) e a busca na literatura (base de dados SciELO e periódicos indexados), onde se utilizou as palavras-chaves que nortearam a revisão. Por fim, foram analisados os artigos que respondiam a problemática norteadora em seu texto, por conseguinte, fora criado fluxograma e quadro que apresentasse os problemas que mais se repetem nos estudos, permitindo o esboço dos resultados almejados.

O processo de seleção e aplicação dos critérios de elegibilidade das produções bibliográficas para este trabalho partiram na análise qualitativa de artigos e trabalhos científicos, em que se selecionou os teóricos que abordassem a Lei $10.639 / 2003$ em sua interface de desafios de implementação municipal na Bahia, que resultou na seleção de o7 trabalhos para demonstrar os resultados. Dos trabalhos selecionados, o4 compuseram artigos de Pesquisa de Campo e os outros o3 foram estudos para dissertações (sendo 02 pesquisa-ação e or pesquisa etnográfica) (ZANELLA, 2012).

\section{Resultados e discussão}

As leis devem ser compreendidas como mecanismos socialmente criadas para fins de se estabelecer normas, regras de convivência em sociedade, permitindo que haja harmonia entre os seus componentes, onde uns e outros entendam que há diferenças de classes, de gênero e orientação sexual, de religiões, por questões étnico-raciais, de descendências ou mesmo de concepções políticas e opiniões. Mas esta interrelação entre os intengrantes da socieade não podem desencaderar errôneas concepções de superioridade e inferioridade pautados por uma questão de diferenças intrínsecas ou extrínsecas entre as pessoas. O que a lei deve garantir é o respeito e a convivência entre as pessoas, com suas particularidades, sejam elas quais forem (LIMA, 20II).

A lei ro.639/2003, a partir do que foi retirado dos estudos de Lima (2011), tem uma função social precípua e legítima: mostrar que as diferenças entre as pessoas existem, mas ao mesmo tempo deixar assente, desde a tenra idade, que ser diferente é que é ser normal. As questões relativas às relações étnicoraciais, onde "racial" é entendido como conceito sociológico e antropológico criado para fins de estudar segmentos de pessoas a partir de características biológicas e que étnico é mais abrangente, indo além que questões biológicas, mas incluindo a cultura, as origens, a história de formação, devem ser trabalhadas em 
sala de aula, sempre visando quebrar o padrão de discriminação racial, fortemente presente no cotidiano brasileiro.

Araújo (2015), aprofundando a importância da lei para implementar questões de políticas públicas e ao mesmo tempo tratando da promulgação da Lei 10.639/2003, deixou claro que tratar da história e cultura do continente africano e dos seus descendentes no Brasil foi motivo de criação, no estado da Bahia, em 1985, de um Parecer (089/85) que autorizava a criação da disciplina "Introdução aos estudos africanos", inclusive posteriormente incluindo na Constituição do Estado um artigo valorizando a cultura e a história africana e afro-brasileira nos currículos escolares. Com isso, a Bahia se destacou como o primeiro Estado da Federação a legislar sobre a temática.

Conforme os estudos de Souza, Santos e Eugênio (2015), feitos a partir do discurso pedagógico das gestoras escolares sobre os desafios e os avanços no processo de discussão e implementação da Lei 10639/03 no ensino, feitos em uma escola localizada em Jequié, na Bahia, apontou como principais desafios para implementar a legislação no referido município, a falta de material didático e ausência de uma literatura que aborde de forma eficaz as questões raciais, a ausência de um trabalho docente efetivo quanto à abordagem da disciplina da história e da cultura Afro-brasileira e Africana, a precária formação de professores para abordarem a lei $10.639 / 2003$, seus regulamentos e as normas previstas na LDB e nos parâmetros curriculares nacionais, destacando ainda a (falta) de vontade política.

Um dos desafios que foram enfrentados na cidade, encontrado fora dos ambientes escolares, foi a intolerância religiosa principalmente com aquelas de matrizes africanas (a exemplo do Candomblé). Afirmou Souza, Santos e Eugênio (2015, p. 189) que "o discurso mostra a existência da perseguição religiosa caracterizada como intolerância, não aceitação das diferenças ou crenças religiosas. A religiosidade afro-brasileira ainda é alvo de muitos preconceitos”.

Santana et al. (2017), traçando um estudo a partir de entrevistas feitas em uma escola na cidade de Itapetinga-Bahia, demonstrou que as principais dificuldades encontradas para incrementar a Lei Io.639/2003, tornando-a uma norma efetiva e produtora de resultados seja a decorrente da dificuldade que a escola possui de quebrar a bagagem trazida pelos alunos de suas próprias casas e da comunidade de onde vieram, pois percebeu-se, a partir das respostas levantadas, que as famílias possuem certa culpa pelo fato dos alunos trazerem e manifestarem atitudes de racismo e preconceito racial.

Como citam os referidos autores, deve-se atentar que a academia também é um ambiente onde "o preconceito e a discriminação racial são aprendidos e reafirmados, também, na instituição escolar, através de seu currículo, das falas dos professores, do tratamento desigual dispensado às crianças negras em relação às crianças brancas" (SANTANA ET AL., 2017, p. 14). 
Para Souza (2017), que ao realizar uma investigação de como o município de Lapão se organiza para fins de implementar a política de formação continuada para professores para fins de abordarem as questões etnicorraciais, deixou assente que o município apresenta um bom aparato legal sobre a temática. Porém, ressaltou uma deficiência visível quanto ao tipo de abordagem da temática, sendo necessário criar um programa curricular que torne o ensino da história e cultura da África e dos descendentes como integrante permanente dentre os conteúdos, modificando o estilo atual esporádico de abordagem. Outro ponto destacado quanto a deficiência na abordagem especificada, está no fato de que os professores não possuem formação específica para trabalharem com as determinações legais em sala de aula, especialmente aqueles que trabalham com disciplina de História, língua Portuguesa e Artes.

A dissertação de mestrado realizada por Gomes (2015) traçou um estudo sobre as Relações Étnicoraciais na Escola baseadas em um diálogo com professoras e estudantes das séries iniciais do ensino fundamental, cujo resultado foi possível a partir de uma pesquisa desenvolvida em uma escola municipal do município de Teixeira de Freitas, no Extremo Sul da Bahia. Considerando o caráter relevante de importante luta social e de política pública, a autora afirmou que a Lei no $10.639 / 2003$ permitiu que inúmeras iniciativas fossem criadas no âmbito educacional, por ações do Ministério da Educação, voltados para a formação de professores para fins de trabalharem com a diversidade étnico-racial, a produção de materiais didáticos sobre a temática, o fortalecimento no campo investigativo $\mathrm{e}$ desenvolvimento de pesquisas.

$\mathrm{Na}$ escola em que o estudo foi realizado, ainda que o Projeto Político Pedagógico (PPP) tenha a previsão da importância das lutas e que a semana da Consciência Negra são fundamentais para a coletividade, são verificados que há deficiências quanto a aplicabilidade da legislação que torna obrigatório o ensino da História e Cultura da África e do Afrodescendente, a exemplo a carência de livros que abordem os conteúdos narrados, com a presença de uma única coleção que seja voltado para a temática específica. Verificou-se que o projeto político era fraco quando abordava o tema da importância da África no Brasil, e que era evidente a falta de preparo formativo dos professores (GOMES, 2015).

Para fins de resumir de forma sistemática os principais desafios enfrentados pelos municípios baianos quanto a aplicabilidade da Lei $10.639 / 2003$, foi apresentado o quadro-resumo abaixo traçando os pontos de maior destaque da literatura analisada, visando ao final elencar quais problemas se repetem nas escolas escolhidas dentre os municípios objetos de estudo, traçando uma realidade do Estado quanto a dificuldade em implementar as questões étnico-raciais nas escolas. 
Quadro I. Informações sintetizadas dos trabalhos selecionados para a revisão sistemática

\begin{tabular}{|c|c|c|c|}
\hline $\begin{array}{l}\text { Autor (es) e Ano } \\
\text { de publicação }\end{array}$ & Cidade & $\begin{array}{l}\text { Sujeitos } \\
\text { Pesquisa }\end{array}$ & $\begin{array}{l}\text { Dificuldade da implementação da Lei. } \\
\text { 10.639/2003 }\end{array}$ \\
\hline $\begin{array}{l}\text { (Programa de } \text { Pós- } \\
\text { graduação } \\
\text { Formação de } \\
\text { Professores da } \\
\text { Educação Básica). }\end{array}$ & Ilhéus - BA & $\begin{array}{lr}\text { I8 crianças } & \text { (o9 } \\
\text { meninas e } & \text { o9 } \\
\text { meninos); } & \\
\text { o2 docentes } & \text { de } \\
\text { pedagogia } & \text { or } \\
\text { estagiária } & \text { em } \\
\text { pedagogia. } & \end{array}$ & $\begin{array}{l}\text { Mitigação das secretarias } \\
\text { desconhecimento da temática étnico- } \\
\text { racial; dificuldades em aceitar as questões } \\
\text { históricas da temática, o racismo } \\
\text { estrutural e a intolerância religiosa por } \\
\text { parte dos professores; desconhecimento } \\
\text { total sobre a Lei Io.639/2003 por parte dos } \\
\text { responsáveis dos alunos e de alguns } \\
\text { professores. }\end{array}$ \\
\hline $\begin{array}{l}\text { SOUZA; } \\
\text { SANTOS; } \\
\text { EUGENIO, 20I5. } \\
\text { (Revista Práxis } \\
\text { Educacional) }\end{array}$ & Jequié - BA & $\begin{array}{l}03 \text { Funcionários } \\
\text { da Secretaria } \\
\text { Municipal de } \\
\text { Educação. }\end{array}$ & $\begin{array}{l}\text { Falta de material didático e de literatura } \\
\text { acerca da temática étnico-racial; falta de } \\
\text { trabalho docente com a disciplina } \\
\text { História e Cultura Afro-brasileira e } \\
\text { Africana; precária formação continuada } \\
\text { de professores; e a ausência de vontade } \\
\text { política. }\end{array}$ \\
\hline $\begin{array}{l}\text { EUGÊNIO; } \\
\text { SANTOS; } \\
\text { SOUZA, } 2016\end{array}$ & Jequié - BA & $\begin{array}{lr}\text { o3 servidores } & \text { da } \\
\text { Secretaria } & \text { de } \\
\text { Educação } & \text { e } \\
\text { Cultura. } & \end{array}$ & $\begin{array}{l}\text { Necessidade de criar um Decreto } \\
\text { municipal que normatizasse o Ensino das } \\
\text { Relações étnico-raciais como disciplina do } \\
\text { fundamental, falta de livros didáticos que } \\
\text { abordem a Ensino de História e Cultura } \\
\text { Afro-brasileira e Indígena e o Ensino de } \\
\text { História e Cultura Afro-brasileira e } \\
\text { Africana. }\end{array}$ \\
\hline $\begin{array}{l}\text { SANTANA et al., } \\
2017\end{array}$ & $\begin{array}{l}\text { Itapetinga } \\
\text { BA }\end{array}$ & $\begin{array}{l}\text { o4 entrevistados } \\
\text { (or diretor, oI } \\
\text { coordenador } \\
\text { pedagógico, e } 02 \\
\text { professores). }\end{array}$ & $\begin{array}{l}\text { Foram destacados a aplicabilidade prática } \\
\text { e a importância da disciplina "Cultura } \\
\text { Afro Indígena" na escola onde ocorreu a } \\
\text { entrevista. As maiores indicações } \\
\text { indicadas foram a limitado conhecimento } \\
\text { acerca da História Africana e } \\
\text { Africanidades, a ausência de curso de } \\
\text { formação na área específica para diretores } \\
\text { e coordenadores escolares. }\end{array}$ \\
\hline $\begin{array}{l}\text { (Mestrado } \\
\text { Profissional em }\end{array}$ & Lapão - BA & $\begin{array}{l}\text { 2I participantes } \\
\text { (dentre alunos, } \\
\text { diretores e } \\
\text { professores) }\end{array}$ & $\begin{array}{l}\text { Ausência de cursos para capacitaçao dos } \\
\text { professores do ensino básico para fins de } \\
\text { lecionarem acerca da Lei ıo.639/2003; falta } \\
\text { de previsão no Projeto Político } \\
\text { Pedagógico sobre a Lei 10.639/2003; }\end{array}$ \\
\hline
\end{tabular}




\begin{tabular}{|c|c|c|c|}
\hline $\begin{array}{l}\text { Educação: } \\
\text { Currículo, } \\
\text { Linguagens } \\
\text { Inovações } \\
\text { Pedagógicas) }\end{array}$ & & & $\begin{array}{l}\text { Desconhecimento, por parte dos } \\
\text { docentes, sobre a Lei em seu texto } \\
\text { primário, mas aplicam conteúdos } \\
\text { discutidos pela Secretaria Municipal de } \\
\text { Educação objetivando frisar o combate ao } \\
\text { Racismo e Intolerância religiosa. }\end{array}$ \\
\hline $\begin{array}{l}\text { LIMA, } 2020 \\
\text { (Pós-Graduação } \\
\text { Mestrado } \\
\text { profissional em } \\
\text { Ensinor das } \\
\text { Relações Étnicos } \\
\text { Raciais/PPGER) }\end{array}$ & Itabuna - BA & o9 docentes & $\begin{array}{l}\text { Falta de aperfeiçoamento docente na } \\
\text { temática de estudos étnico-raciais; } \\
\text { ausência de material didático que } \\
\text { contextualize a história da cultura e } \\
\text { transgressões dos povos negros; e } \\
\text { desconhecimento da Lei Io.639/2003. }\end{array}$ \\
\hline $\begin{array}{l}\text { SANTANA; } \\
\text { ALVES, 2010 } \\
\text { (Revista } \\
\text { Travessias) }\end{array}$ & $\begin{array}{l}\text { Itapetinga } \\
\text { BA }\end{array}$ & $\begin{array}{l}\text { I5 professores } 03 \\
\text { coordenadores } \\
\text { pedagógicos }\end{array}$ & $\begin{array}{l}\text { Falta de um projeto/plano de ação para as } \\
\text { escolas voltado para fins de capacitar } \\
\text { professores sobre a Lei; ausência de } \\
\text { políticas públicas voltadas para a } \\
\text { formação de professores; desigualdade } \\
\text { social, responsável por fortalecer o } \\
\text { preconceito; falta de livros didáticos; } \\
\text { resistência por parte de alguns } \\
\text { professores. }\end{array}$ \\
\hline
\end{tabular}

Fonte: Autor.

Assim, o que mais se repetiu no quesito "Dificuldade da implementação da Lei. 10.639/2003" nos municípios de Itabuna, Jequié, Lapão, Teixeira de Freitas, Itapetinga e Ilhéus, foram o desconhecimento do que está previsto na Legislação sobre ensino e relações étnico-raciais, falta de preparo dos professores ou falta de cursos para aperfeiçoamento, ausência parcial ou total de políticas públicas para a diversidade, material sobre a temática em pequena quantidade ou sem acesso a publicações atuais.

Conforme o que foi apresentado a partir dos desafios de alguns municípios da Bahia que tiveram trabalhos publicados nos últimos dez anos, verificou-se que os principais desafios para implementar o Ensino da História e da Cultura Africana e Afro-brasileira no ensino fundamental, conforme determinação da Legislação educacional, é superar lacunas a partir de um trabalho da escola, da comunidade e do Poder Público, de forma conjunta, trazendo como resultado mediato uma melhora no ensino baiano, redução das desigualdades e que provoque uma quebra nos paradigmas sociais acerca do racismo e da discriminação. 


\section{Conclusão}

Procurando compreender o impacto da Lei Io.639/2003 nos currículos da Bahia na atualidade, fezse uma análise a partir de estudos que demonstrassem como vem sendo implementada a referida legislação em alguns municípios baianos, a partir de uma análise sistemática. Ainda que não sejam esgotados os estudos sobre os problemas acerca da temática quanto as falhas no ensino étnico-racial, apontando as lacunas no Estado como um todo.

Assim, a partir da indagação sobre quais os problemas mais recorrentes e que devem ser objeto de políticas públicas, viu-se que os principais são a falta de conhecimento da Lei e das alterações na LDB sobre a obrigatoriedade do ensino da história e cultura africana e do afrodescendente, a precária formação dos profissionais de ensino fundamental acerca da temática, ausência de material didático e melhora nos currículos educacionais e nos Projetos Políticos Pedagógicos para abarcar a alteridade e valorizar as diferentes culturas.

Sem escopo de esgotar as investigações, mas apenas traçando linhas gerais sobre uma temática tão importante e que deve ser incrementar em todo o País, principalmente no Estado da Bahia, por sua cultura e diversidade étnico-racial, é que propõe a continuidade do presente estudo, principalmente buscando englobar outros segmentos da sociedade, além dos muros da Escola, para investigar as raízes do racismo e da discriminação e os meios de quebrar essas barreiras socialmente impostas àqueles mais vulneráveis: negros, pobres, indígenas.

\section{Referências}

ALMEIDA, Marco Antônio Bettine de; SANCHEZ, Lívia Pizauro. Implementação da Lei Io.639/2003 competências, habilidades e pesquisas para a transformação social. Pro-posições, [s. l.], ano 2017, p. 55-80, V. 28, N.I jan./abr. 2017. Disponível em: 〈http://www.scielo.br/scielo.php?script=sci_arttext\&pid=Soro373072017000100055>. Acesso em: 4 jan. 2021.

ARAÚJO, Jurandir de Almeida. A efetivação da Lei ıo.639/2003 na percepção dos militantes/professores negros baianos. Revista Eletrônica de Educação, [s. l.], ano 2015, v. 9, n. 3, p. 216-232, 2015. Disponível em: <http://www.reveduc.ufscar.br/index.php/reveduc/issue/view/20>. Acesso em: I4 jan. 202I.

BRAIL. MEC. Parecer CNE/CP n. 3 , de ro de março de 2004: Institui Diretrizes Curriculares Nacionais para a Educação das Relações Étnico-Raciais e para o Ensino de História e Cultura Afro-Brasileira e Africana, Brasília/DF: SECAD/MEC. 2004. Disponível em: 〈http://portal.mec.gov.br/dmdocuments/cnecp_o03.pdf〉. Acesso em: is jan. 202I.

BRASIL. Lei no $\mathbf{1 0 . 6 3 9 , ~ d e ~} 9$ de janeiro de 2003. Altera a Lei no 9.394, de 20 de dezembro de 1996, que estabelece as diretrizes e bases da educação nacional, para incluir no currículo oficial da Rede de Ensino a obrigatoriedade da temática "História e Cultura Afro-Brasileira", e dá outras providências. [S. l.], 2003. Disponível em: 〈http://www.planalto.gov.br/ccivil_03/leis/2003/1ro.639.htm〉. Acesso em: 7 jan. 202 I. 
BRASIL. Lei no 9.394, de 20 de dezembro de 1996. Estabelece as diretrizes e bases da educação nacional. [S. l.], 1996. Disponível em:〈http://www.planalto.gov.br/ccivil_03/leis/19394.htm〉. Acesso em: 7 jan. 202I.

EUGÊNIO, Benedito Gonçalves; SANTOS, José Jackson Reis dos; SOUZA, Janyne Barbosa de. Currículo e relações etnicorraciais: a implementação da disciplina "História da Cultura Afro-Brasileira" no município de Jequié/Bahia. Revista e-Curriculum, São Paulo/SP, v. I4, n. 4, p. I288-1309, Out./Dez. 2016. Disponível em: < https://www.redalyc.org/articulo.oa?id=76649457007 >. Acesso em: I2 jan. 2021.

FONTOURA, Elisângela de Oliveira. Lei Io.639/2003: uma análise de sua relevância no contexto escolar. EDUCERE, XIII Congresso Nacional de Educação, ano 2017, p. 7039-7052, 2017. Disponível em: 〈https://educere.bruc.com.br/arquivo/pdf2017/24954_I2904.pdf〉. Acesso em: I3 jan. 2021.

GOMES, Jackeline Santana. Relações étnico-raciais na escola: diálogo com professoras e crianças das séries iniciais do ensino fundamental. Orientador: Dr. Rachel Oliveira. 2015. ıo6 p. Dissertação (Mestrado) - Universidade Estadual de Santa Cruz - Programa de Pós-Graduação Formação de Professores da Educação Básica-PPGE, Ilhéus-Bahia, 2015.

GOMES, Nilma Lino (org). Práticas pedagógicas de trabalho com relações étnico-raciais na escola na

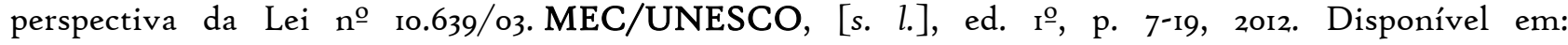
<http://ciclopermanenteufmg.com.br/wp-content/uploads/2018/o7/Pr\%C3\%Articas-

Pedag\%C3\%B3gicas-de-Trabalho-com-a-Lei-ıo.639_03.pdf $>$. Acesso em: 28 dez. 2020.

LIMA, Carla Fernanda Santos. Tessitura em Formação: Por uma educação antirracista. Orientador: Drª . Célia Regina da Silva. 2020. 89 p. Dissertação (Mestrado) - Universidade Federal do Sul da Bahia Programa de Pós-Graduação em Ensino e Relações Étnico-Raciais, Itabuna-Bahia, 2020.

LIMA, Carla Fernanda Santos. Tessitura em Formação: Por uma educação antirracista. Orientador: Drª . Célia Regina da Silva. 2020. 89 p. Dissertação (Mestrado) - Universidade Federal do Sul da Bahia Programa de Pós-Graduação em Ensino e Relações Étnico-Raciais, Itabuna-Bahia, 2020.

LIMA, Ivaldo Marciano de França. Por uma história a partir dos conceitos. Revista a Cor das Letras, [s. l.], $\quad$ v. I2, $\quad$ n. $\quad$ I, $2011 . \quad$ Disponível 〈http://periodicos.uefs.br/index.php/acordasletras/article/view/I488>. Acesso em: 5 jan. 2021.

NUNES, Érica Melanie Ribeiro. Políticas públicas e marcos legais para educação antirracista no brasil: da Constituição de 1988 à lei ro.639/o3. Igualitária: Revista do Curso de História da Estácio, [s. 1.], p. I-24, 2014 . Disponível em: <http://revistaadmmade.estacio.br/index.php/historiabh/article/view/882/educa\% $\mathrm{C}_{3} \% \mathrm{~A}_{7 \%} \mathrm{C}_{3 \%} \mathrm{~A}_{30} \% 2$ oantirracista $>$. Acesso em: is jan. 2021.

QUEIROZ, Delcele Mascarenhas; MACÊEO, Marluce de Lima. A produção de estudos sobre a lei ı.639 nas regiões Norte e Nordeste. Revista Educação e Políticas em Debate, [s. l.], ano 2013, p. 76-ıo4, jan./jul. 2013. Disponível em: <http://www.seer.ufu.br/index.php/revistaeducaopoliticas/article/view/24062>. Acesso em: 6 jan. 202 I.

RIBEIRO, Darcy. O Povo Brasileiro: A formação e o sentido do Brasil. [S. l.]: Companhia das Letras, I995. $477 \mathrm{p}$. 
RIBEIRO, Débora. A Lei no $10.639 / 03$ : limites e perspectivas para a educação das relações étnicoraciais. EDUCERE, XII Congresso Nacional de Educação - PUCPR, p. 26188-26207, Out. 2015. Disponível em: 〈https://educere.bruc.com.br/arquivo/pdf2015/16356_7463.pdf 〉. Acesso em: I4 jan. 202I.

SANTANA, José Valdir Jesus de; ALVES, Joeslei Santos. Tensões e desafios para a implantação da lei ı.639/03 no município de Itapetinga - BA. Revista África e Africanidades, [s. l.], ano 2, n. 8, p. I-18, Fev. 2010.

SANTANA, José Valdir Jesus de, et al; Educação para as relações étnico-raciais em uma escola pública do município de Itapetinga-BA. Revista Travessias, [s. l.], v. II, n. I, p. 2II-243, jan./abr. 2017. Disponível em: 〈http://e-revista.unioeste.br/index.php/travessias/article/view/I576I . Acesso em: 7 jan. 2021.

SOUZA, Janyne Barbosa de; SANTOS, José Jackson Reis dos; EUGÊNIO, Benedito Gonçalves. Avanços e desafios no processo de implementação da Lei I0639/o3 na Rede Municipal de Ensino de Jequié-Ba: os discursos do campo recontextualizador oficial. Práxis Educacional, Vitória da Conquista/ES, v. II, n. I8, p. 177-197, jan./abr. 2015. Disponível em: $\langle$ https://periodicos2.uesb.br/index.php/praxis/article/view/8o6〉. Acesso em: I4 jan. 202I.

SOUZA, Marisa Santos de. A implementação das Leis $10.639 / 2003$ e a $11.645 / 2008$ na rede ensino de Lapão: Uma proposta de intervenção curricular intercultural. Orientador: Drậ. Jamile Borges da Silva. 2017. I3I p. Dissertação (Mestrado) - Universidade Federal da Bahia - Mestrado Profissional em Educação Currículo, Linguagens e Inovações Pedagógicas, Salvador-Bahia, 2017.

ZANELLA, Liane Carly Hermes. Metodologia de estudo e pesquisa em administração. Florianópolis: Departamento de Ciências da Administração. CAPES, UAB, 2012. 